\title{
Article \\ Characterization of the $m b s A$ Gene Encoding a Putative APSES Transcription Factor in Aspergillus fumigatus
}

\author{
Yong-Ho Choi ${ }^{1,+}{ }^{\text {, Sang-Cheol Jun }}{ }^{1,+}{ }^{+}$, Min-Woo Lee ${ }^{2}$, Jae-Hyuk Yu ${ }^{3,4, *}$ and Kwang-Soo Shin ${ }^{1, *}$ (i) \\ 1 Department of Microbiology, Graduate School, Daejeon University, Daejeon 34520, Korea; \\ youngho1107@gmail.com (Y.-H.C.); scjun@jbnu.ac.kr (S.-C.J.) \\ 2 Soonchunhyang Institute of Medi-Bio Science, Soonchunhyang University, Cheonan 31151, Korea; \\ mwlee12@sch.ac.kr \\ 3 Department of Bacteriology, University of Wisconsin-Madison, Madison, WI 53706, USA \\ 4 Department of Systems Biotechnology, Konkuk University, Seoul 143-701, Korea \\ * Correspondence: jyu1@wisc.edu (J.-H.Y.); shinks@dju.kr (K.-S.S.); Tel.: +1-608-262-4696 (J.-H.Y.); \\ +82-42-280-2439 (K.-S.S.); Fax: +1-608-262-2976 (J.-H.Y.); +82-42-280-2608 (K.-S.S.) \\ + These authors contributed equally to this work.
}

Citation: Choi, Y.-H.; Jun, S.-C.; Lee, M.-W.; Yu, J.-H.; Shin, K.-S.

Characterization of the $m b s A$ Gene Encoding a Putative APSES Transcription Factor in Aspergillus fumigatus. Int. J. Mol. Sci. 2021, 22, 3777. https://doi.org/10.3390/ ijms22073777

Academic Editor: Stephen Bustin

Received: 16 February 2021

Accepted: 5 April 2021

Published: 6 April 2021

Publisher's Note: MDPI stays neutral with regard to jurisdictional claims in published maps and institutional affiliations.

Copyright: () 2021 by the authors. Licensee MDPI, Basel, Switzerland. This article is an open access article distributed under the terms and conditions of the Creative Commons Attribution (CC BY) license (https:// creativecommons.org/licenses/by/ $4.0 /)$.

\begin{abstract}
The APSES family proteins are transcription factors (TFs) with a basic helix-loop-helix domain, known to regulate growth, development, secondary metabolism, and other biological processes in Aspergillus species. In the genome of the human opportunistic pathogenic fungus Aspergillus fumigatus, five genes predicted to encode APSES TFs are present. Here, we report the characterization of one of these genes, called $m b s A$ (Afu7g05620). The deletion ( $\Delta$ ) of $m b s A$ resulted in significantly decreased hyphal growth and asexual sporulation (conidiation), and lowered mRNA levels of the key conidiation genes $a b a A, b r l A$, and wet $A$. Moreover, $\triangle m b s A$ resulted in reduced spore germination rates, elevated sensitivity toward Nikkomycin Z, and significantly lowered transcripts levels of genes associated with chitin synthesis. The $m b s A$ deletion also resulted in significantly reduced levels of proteins and transcripts of genes associated with the SakA MAP kinase pathway. Importantly, the cell wall hydrophobicity and architecture of the $\triangle m b s A$ asexual spores (conidia) were altered, notably lacking the rodlet layer on the surface of the $\triangle m b s A$ conidium. Comparative transcriptomic analyses revealed that the $\triangle m b s A$ mutant showed higher mRNA levels of gliotoxin (GT) biosynthetic genes, which was corroborated by elevated levels of GT production in the mutant. While the $\triangle m b s A$ mutant produced higher amount of GT, $\triangle m b s A$ strains showed reduced virulence in the murine model, likely due to the defective spore integrity. In summary, the putative APSES TF MbsA plays a multiple role in governing growth, development, spore wall architecture, GT production, and virulence, which may be associated with the attenuated SakA signaling pathway.
\end{abstract}

Keywords: APSES transcription factor; Aspergillus fumigatus; MbsA; rodlet layer; gliotoxin; virulence; transcriptomics

\section{Introduction}

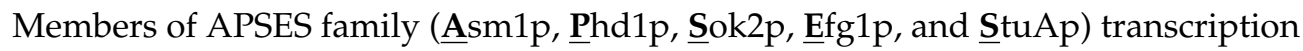
factors (TFs) regulate growth, morphogenesis, development, secondary metabolism, and other biological processes in fungi [1]. This group of proteins comprises a family of TFs that share a highly conserved helix-loop-helix DNA-binding motif [2-5]. Based on correlation of APSES domain, this proteins are divided into four major groups (clade A to D) [1]. Each of these proteins has been shown to play a critical role in governing fungal morphogenesis, development, and virulence.

In the genome of the opportunistic human pathogenic fungus Aspergillus fumigatus, five genes are predicted to encode APSES proteins: Afu7g05620, $\operatorname{rgdA}$, stuA, $x b p A$, and afpA (Afu5g11390). The clade C-II APSES protein StuA controls asexual reproduction, conidiophore formation, and conidia germination [6]. Mutants deficient in stuA produce 
abnormal conidiophores and low numbers of dysmorphic conidia [6]. In addition, StuA regulates secondary metabolite biosynthetic genes, morphogenesis regulating genes, and allergen encoding genes [6,7]. RgdA, which belongs to clade A-I, also plays a multiple role in governing growth, development, fungal toxin production, and virulence via attenuation of PKA and SakA signaling [8]. The hyphal growth, asexual sporulation, and conidia germination are decreased by the absence of $r g d A$. Moreover, the conidia wall architecture and hydrophobicity are changed in the $\operatorname{sgd} A$ mutant [8]. These findings suggest that in addition to functioning as a transcriptional repressor during conidiation, RgdA may govern other cellular processes in A. fumigatus.

However, functions of the other APSES TFs including Afu7g05620 gene product in Aspergillus have remained to be elucidated. Previously, flucytosine-responsive Mbp1/Swi4like protein was designated as Mbs1 in Cryptococcus neoformans [9]. So, we named Afu7g05620 (XP_748947.1) gene as mbs A (Mbp1- and Swi6-like protein A). In this study, we have characterized functions of the putative APSES gene $m b s A$ in A. fumigatus. Our series of genetic, biochemical, genomic, histological, and virulence studies have revealed that MbsA plays a multiple role in governing cellular proliferation, asexual development, cell wall architecture, spore integrity, gliotoxin production, virulence, as well as proper SakA MAP kinase signaling.

\section{Results}

\subsection{Summary of A. fumigatus $M b s A$}

The ORF of $m b s A$ in A. fumigatus Af293 (Afu7g05620) consists of 2806 bp nucleotides with two introns, and is predicted to encode an 898 amino acid length protein. As shown in Figure 1A, the predicted MbsA protein has a KilA-N domain (117 to 200 aa) in the Nterminal region, three ankyrin repeat-containing domains in the middle region (446 to 475 , 516 to 559,595 to 623 aa), and a coiled-coil domain at the C-terminal region. The KilA-N domain amino acid sequence of MbsA of A. fumigatus shows $97.6 \sim 100 \%$ identity with MbsAlike proteins of other Aspergillus species. On the other hand, it shows only $30.8 \sim 53.5 \%$ amino acid sequence identity with other APSES proteins of A. fumigatus (StuA and RgdA) and Mbp1 of Saccharomyces cerevisiae (data not shown). In the unrooted phylogenetic analysis based on the amino acid sequence of KilA-N domain, MbsA homologs of Aspergillus are clustered in the same group, RgdA of A. fumigatus (AfuRgdA) and Mbp1 of S. cerevisiae form another group, and StuA of A. fumigatus (AfuStuA) is distinctly related (Figure 1B). We examined levels of the $m b s A$ mRNA throughout the lifecycle and found that there were no differences in all developmental phases except vegetative phase (Figure 1C).

\subsection{MbsA Affects Vegetative Growth and Conidial Development}

To investigate the functions of MbsA, the wild type (WT), $m b s A$ deletion mutant, and complemented strains $\left(C^{\prime}\right)$ were inoculated onto solid glucose minimal medium with $0.1 \%$ yeast extract (MMY) and incubated for 3 days. The colony diameter of $\triangle m b s A$ mutant was smaller (about 25\%) than that of WT and $\mathrm{C}^{\prime}$ strains (Figure 2A). The number of conidia per plate produced by $\triangle m b s A$ mutant was lower than that of $\mathrm{WT}$ and $\mathrm{C}^{\prime}$ strains (Figure $2 \mathrm{~B}$ ). In addition, mRNA expression levels of key asexual developmental regulators, $a b a A, b r l A$, and wet $A$ were significantly lowered in the $\triangle m b s A$ mutant (Figure $2 C$ ). These results suggest that $\mathrm{MbsA}$ is required for proper vegetative growth and conidiation in A. fumigatus. We analyzed the germination rate of the $\triangle m b s A$ conidia in comparison to those of WT and $C^{\prime}$ strains in triplicate. Germination rate of the $\triangle m b s A$ conidia was significantly reduced compared to other strains. Germination rate of the $\triangle m b s A$ conidia was $33 \%$ lower than that of WT and $\mathrm{C}^{\prime}$ strains. Moreover, while about $85 \%$ of WT and $\mathrm{C}^{\prime}$ strains' conidia germinated, only $50 \%$ of the $\triangle m b s A$ spores germinated after $10 \mathrm{~h}$ incubation (Figure 2D). 
A

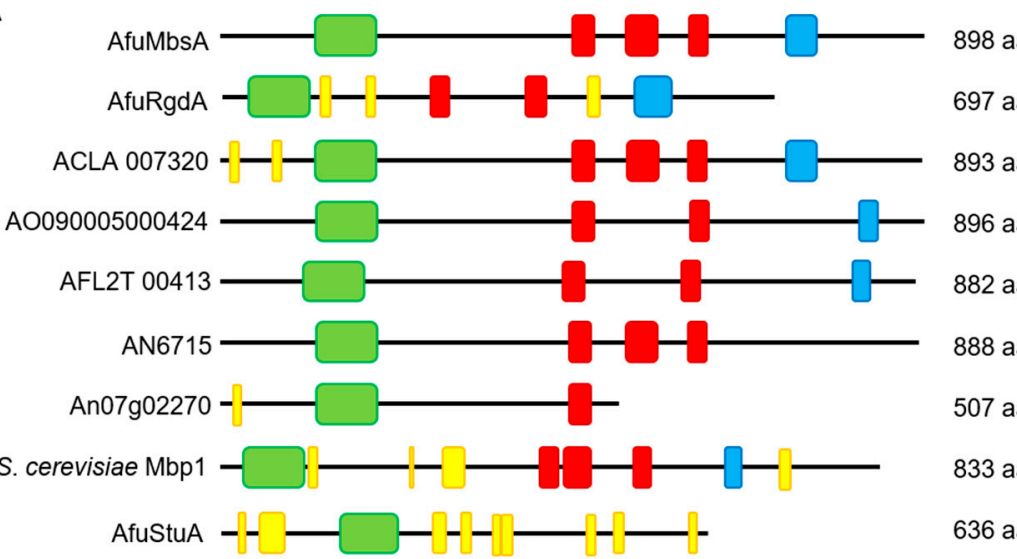

B

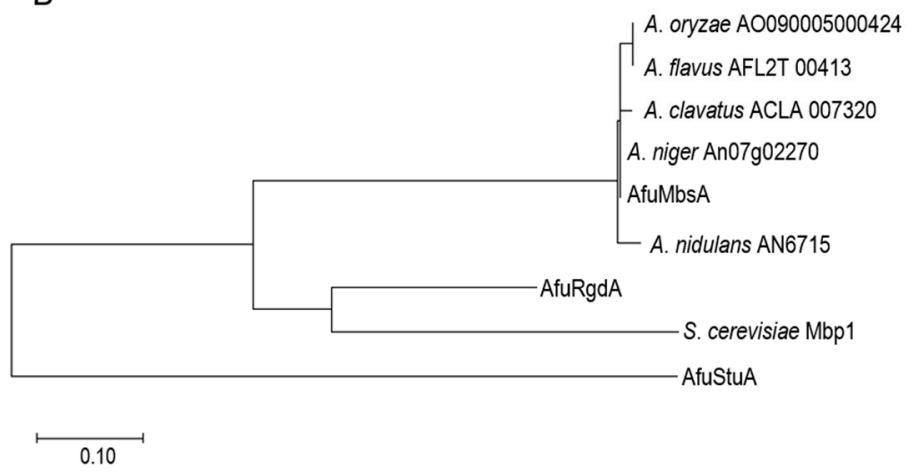

98 aa

697 aa 893 aa

896 aa

882 aa

888 aa

507 aa

833 aa

636 aa

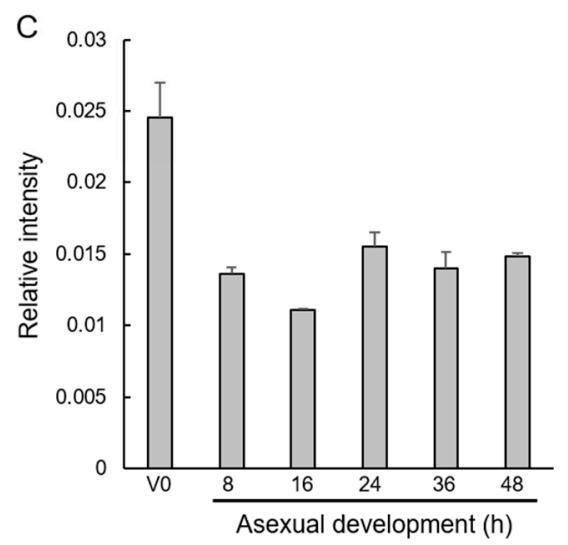

Figure 1. Summary of MbsA. (A) Schematic presentation of the domain structure of the MbsA-like proteins using SMART (http:/ / smart.embl-heidelberg.de, accessed on 10 February 2021). (B) A phylogenetic tree of the MbsA-like proteins in various Aspergillus and Saccharomyces cerevisiae was constructed based on the matrix of pair-wise distances between the KilA-N domain sequences. (C) Levels of $m b s A$ mRNA during the lifecycle of $A$. fumigatus wild type (WT, AF293). The vegetative stage (V0) and time (hours) of incubation in post asexual developmental induction is shown.

\subsection{MbsA Is Involved in Chtin Synthesis in A. fumigatus}

To test a potential role of MbsA in chitin synthesis, we incubated WT, $\triangle m b s A$, and $\mathrm{C}^{\prime}$ strains to solid yeast extract-glucose (YG) containing Nikkomycin Z (NZ). As shown in Figure 3A, the mutant strain showed a significantly reduced radial growth. To further dissect MbsA function in chitin synthesis, we analyzed mRNA levels of chitin synthesisrelated genes. The mRNA levels of genes encoding chitin synthases were decreased significantly by loss of $m b s A$ (Figure 3B). Taken together, these results suggest that MbsA is needed for the synthesis of chitin.

\subsection{MbsA Positively Regulates the SakA MAP Kinase Pathway}

To examine a possible relationship between MbsA and the SakA MAPK pathway that governs stress-response signaling, we analyzed phosphorylation levels of SakA and MpkA, and mRNA levels of SakA MAPK pathway related genes. We carried out antiphospho-p38 and anti-phospho-p42/44 immunoblotting with total soluble protein extracts from WT, $\triangle m b s A$, and $C^{\prime}$ strains treated with $10 \mathrm{mg} / \mathrm{mL}$ Calcofluor White (CFW) for 20 min. A protein with SakA and MpkA predicted molecular mass became transiently phosphorylated in response to the cell wall stress. However, the phosphorylation levels of $\triangle m b s A$ strain was greatly lower than those of WT and $C^{\prime}$ strains (Figure 4A). Transcript levels of SakA MAPK pathway-related genes examined were significantly decreased in the $\triangle m b s A$ mutant (Figure $4 \mathrm{~B})$. These results indicate that MbsA positively regulates the SakA MAPK pathway. 
A
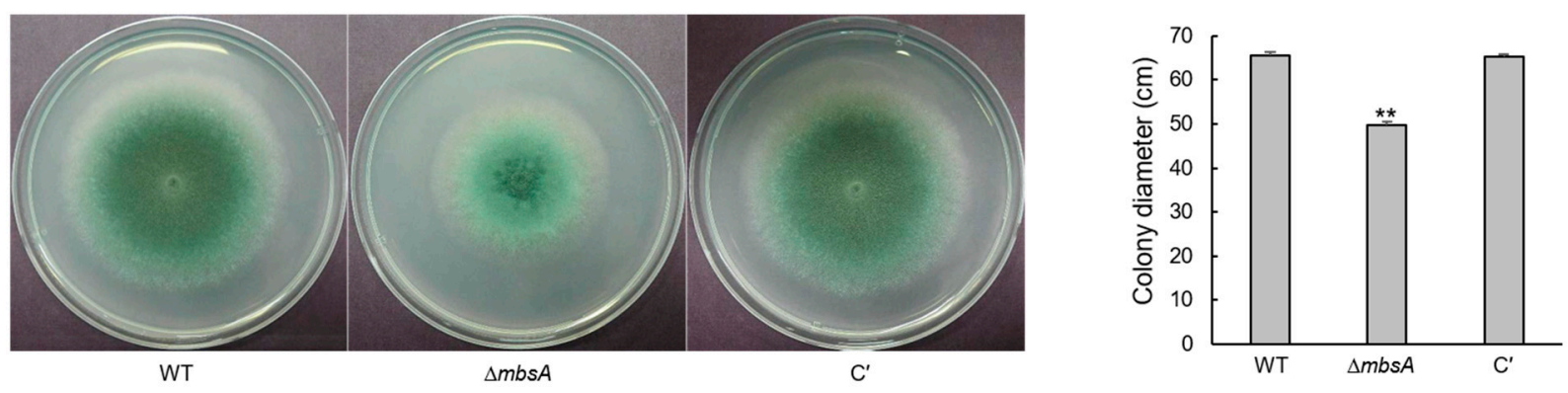

B

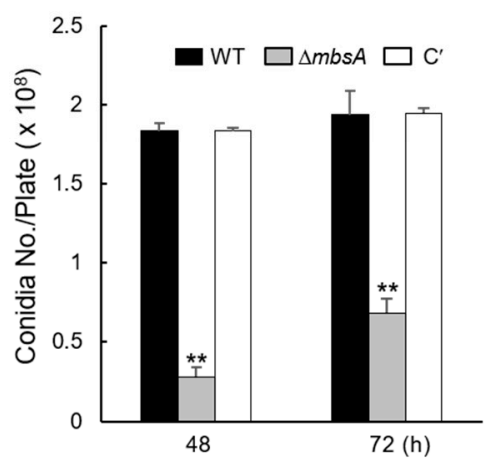

C

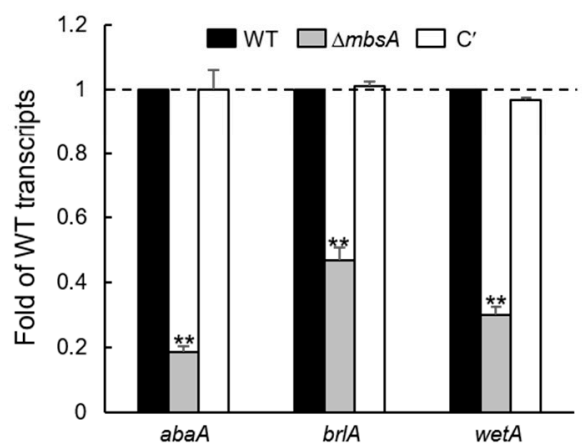

D

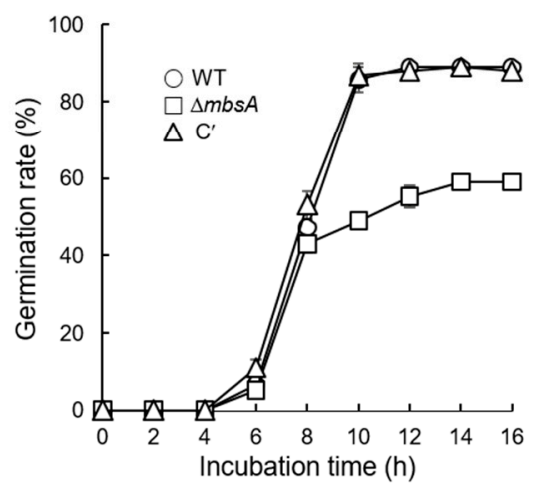

Figure 2. MbsA is required for proper growth, development, and spore germination. (A) Colony photographs and radial growth rate of wild type (WT), $\Delta m b s A$, and complemented $\left(C^{\prime}\right)$ strains point-inoculated on solid glucose minimal medium with $0.1 \%$ yeast extract (MMY) and grown for 3 days. (B) Conidia numbers produced by each strain per plate. (C) mRNA levels of the key asexual developmental regulators in the $\triangle m b s A$ strain relative to WT at 3 days determined by RT-qPCR. Fungal cultures were done in solid MMY and mRNA levels were normalized using the ef1 $\alpha$ gene. (D) Germination rates of A. fumigatus strains when inoculated in liquid $\mathrm{CM}$ at $37^{\circ} \mathrm{C}$. The number of conidia showing germ-tube protrusion was recorded at $2 \mathrm{~h}$ intervals and which is represented as a percentage of the total number of conidia in each microscope field. Data are presented as the mean \pm standard deviation from three independent experiments. ANOVA test: ${ }^{* *} p<0.01$.

\subsection{MbsA Is Necessary for the Conidia Hydrophobicity and Plays a Role in rodA Expression}

The capacity of conidia to reach alveoli is due to the hydrophobicity of conidia and the properties of hydrophobin affect conidial hydrophobicity. To understand the role of MbsA on governing conidial hydrophobicity, we analyzed hydrophobicity of WT, $\triangle m b s A$, and $\mathrm{C}^{\prime}$ colonies using a detergent permeation assay and solvent partitioning assay. As shown in Figure 5A, the detergent solution began to permeate into the colony after $2 \mathrm{~h}$ and completely penetrated at $18 \mathrm{~h}$ in the $\Delta m b s A$ mutant. On the contrary, WT and $\mathrm{C}^{\prime}$ strains still made appeare the detergent solution droplets on the colony surface at $18 \mathrm{~h}$. To further confirm this, we performed microbial adhesion to hydrocarbon (MATS) assay. Hydrophobicity of the $\triangle m b s A$ conidia was decreased about $16 \%$ compared to that of WT and $\mathrm{C}^{\prime}$ conidia (Figure 5B). Then, we extracted the conidial hydrophobin RodA from the conidia and analyzed by SDS-PAGE. The intensity of RodA band was greatly reduced in the $\triangle m b s A$ conidia indicating that the amount of the RodA protein was reduced by the loss of $m b s A$ (Figure 5C). Levels of mRNA of the hydrophobin genes $\operatorname{rod} A$ and $\operatorname{rod} C$ were also significantly decreased in the $\triangle m b s A$ mutant (Figure $5 \mathrm{D}$ ). These results suggest that MbsA positively regulates expression of the $\operatorname{rod} A$ and $\operatorname{rod} C$ genes and subsequently confers proper conidial hydrophobicity. 
A

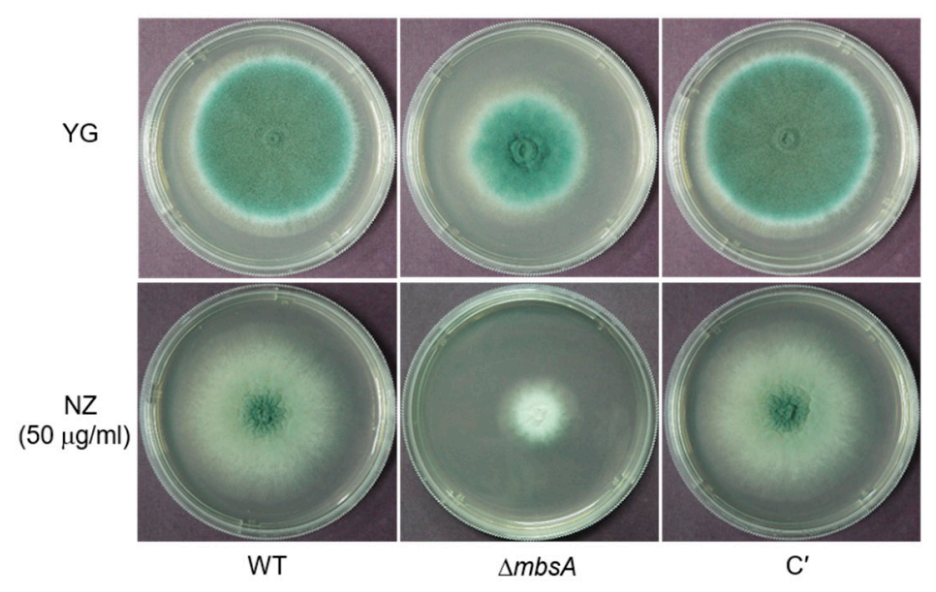

B

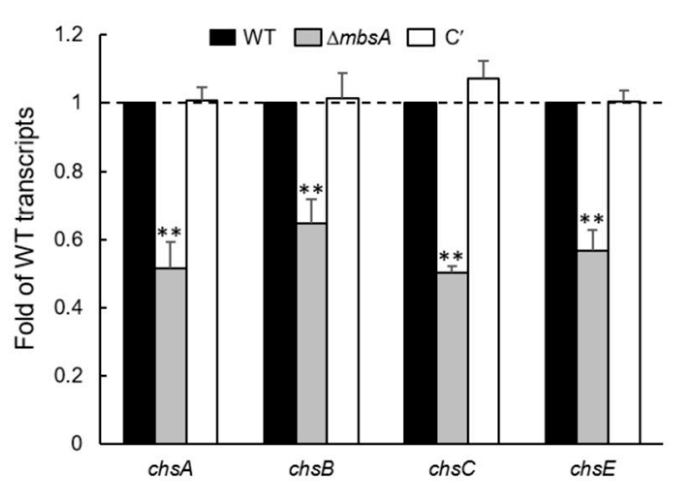

Figure 3. MbsA is necessary for the proper regulation of chitin synthesis. (A) Radial growth of WT, $\Delta m b s A$, and $C^{\prime}$ strains in the presence of Nikkomycin Z (NZ, $50 \mu \mathrm{g} / \mathrm{mL}$ ) following incubation at $37^{\circ} \mathrm{C}$ for $72 \mathrm{~h}$. (B) Chitin synthesis-related genes in WT, $\triangle m b s A$, and $C^{\prime}$ strains analyzed by RT-qPCR. The ef1 $\alpha$ gene as the endogenous control. Statistical differences between strains were evaluated with ANOVA test: ${ }^{* *} p<0.01$.

A

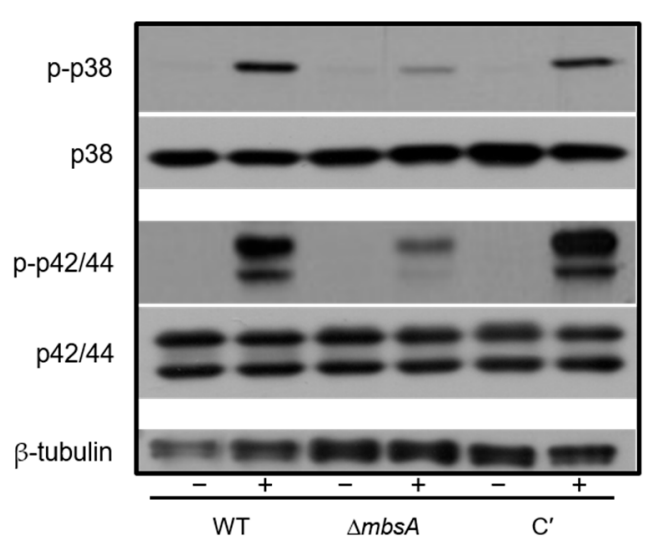

B

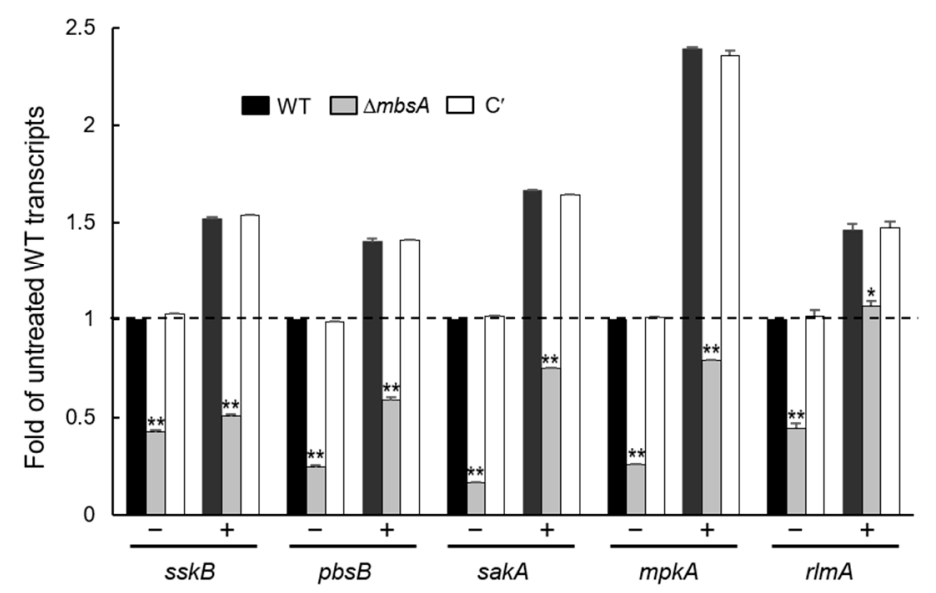

Figure 4. MbsA positively affects the SakA MAPK pathway. (A) Conidia of the indicated strains were grown for $14 \mathrm{~h}$ in MMY medium and treated with $200 \mu \mathrm{g} / \mathrm{mL}$ of Calcofluor White (CFW) (+) or not (-). Aliquots of cell were harvested after $20 \mathrm{~min}$ and used to prepare total protein extracts. Protein extracts were analyzed by immunoblotting with anti-phospho-p38 and anti-phoshpo-p42/44 antibodies. (B) mRNA levels of SakA MAP kinase pathway-related genes in WT, $\Delta m b s A$, and $\mathrm{C}^{\prime}$ strains analyzed by RT-qPCR at the same culture condition. The ef1 $\alpha$ gene as the endogenous control. Statistical differences between strains were evaluated with ANOVA test: ${ }^{* *} p<0.01,{ }^{*} p<0.05$.

\subsection{MbsA Is Required for Proper Spore Wall Formation}

To characterize the link between the change of conidial hydrophobicity and conidia cell wall structure, we observed the fine structure of the conidia of the three strains by using transmission electron microscopy (TEM) and atomic force microscopy (AFM). Structure of the $\triangle m b s A$ conidia surface was strikingly different from that of WT and $C^{\prime}$ conidia, as several irregular protrusions were observed on the surface of $\triangle m b s A$ conidia (Figure $6 \mathrm{~A}$ ). Conidial surfaces were further analyzed by AFM. In contrast to the WT and $C^{\prime}$ conidia that are covered with a crystalline-like array of rodlets, the $\Delta m b s A$ mutant conidial surface was amorphous without any organized structure and the differences were more clearly visible in phase image (Figure 6B). These data suggest that MbsA is necessary for proper conidia wall architecture. 
A

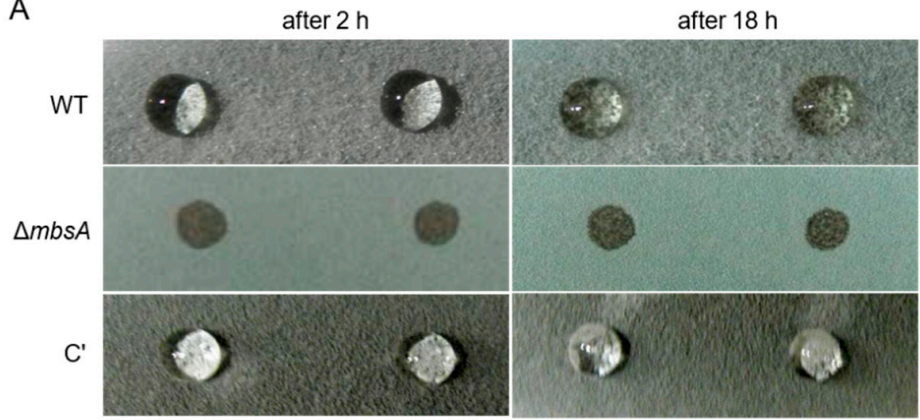

B

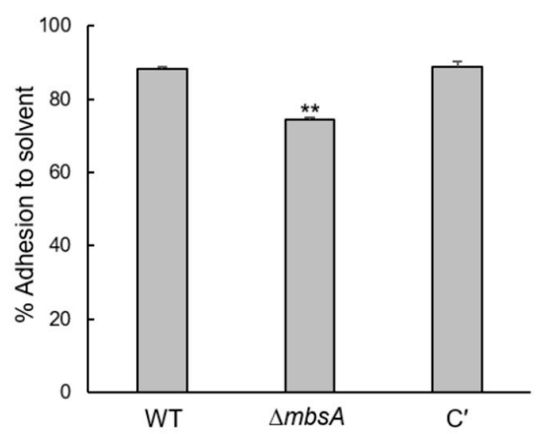

C

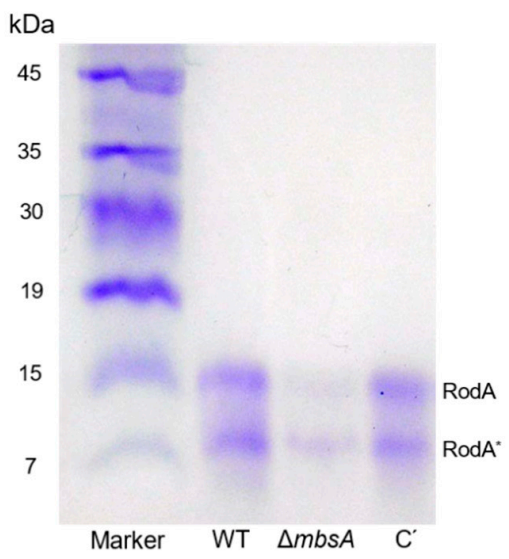

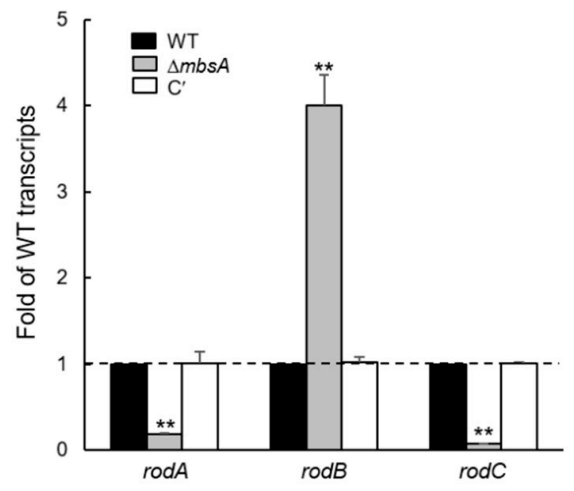

Figure 5. MbsA is needed for proper conidia hydrophobicity. (A) Hydrophobicity test for each strain. Strains were cultured on MMY agar plates for 4 days at $37^{\circ} \mathrm{C}$ and $10 \mu \mathrm{L}$ of a detergent solution (0.2\% SDS, $\left.50 \mathrm{mM} \mathrm{EDTA}\right)$ were dropped onto the surface of a colony. The droplets were observed to penetrate into the colonies. (B) Percentage hydrophobicity of three strains by MATS test. (C) SDS-PAGE analysis of the hydrophobin, RodA of relevant strains. RodA was extracted from the dried conidia $\left(10^{9}\right)$ with hydrofluoric acid (HF). RodA*: degraded form of RodA due to HF treatment. (D) RT-qPCR analysis of hydrophobin genes in WT, $\triangle m b s A$, and $C^{\prime}$ strains. The ef1 $\alpha$ gene as the endogenous control. Statistical differences between strains were evaluated with ANOVA test: ${ }^{* *} p<0.01$.

A

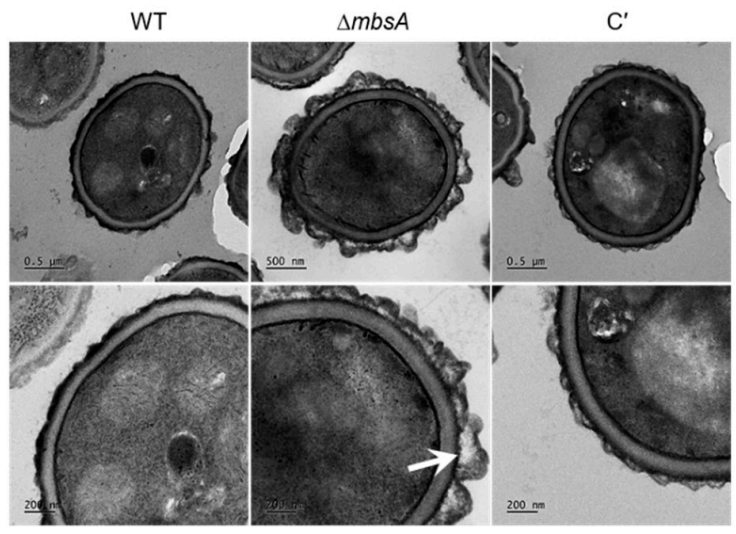

B

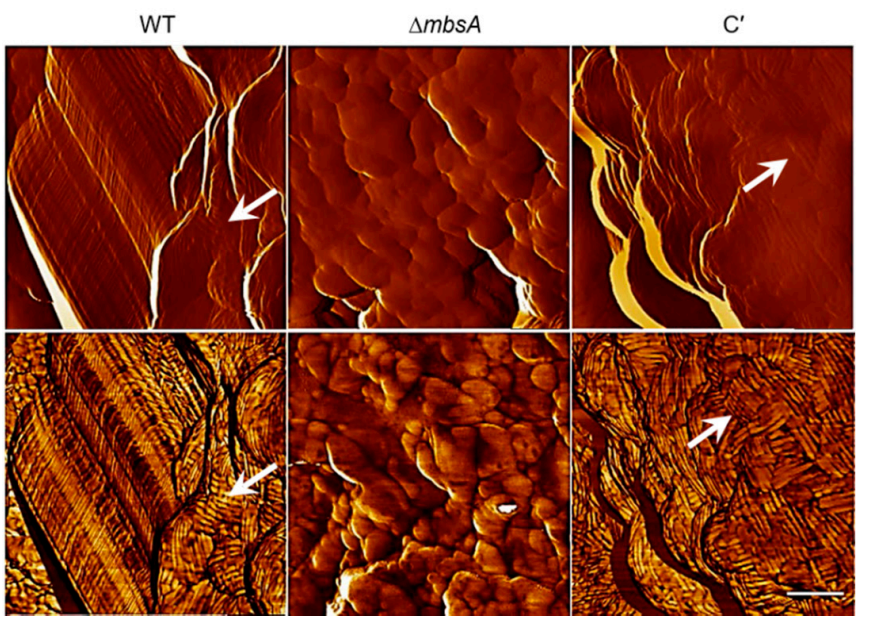

Figure 6. MbsA is needed for proper cell wall architecture and rodlet layer. (A) Transmission electron micrographs of conidia. The conidia were harvested from the cells cultured on MMY medium for 5 days, and they were fabricated as ultra-thin specimens for transmission electron microscopy. (B) Atomic force microscopy (AFM) image of conidial surface of three strains. Upper: amplitude image; Lower: phase image. Rodlets showed only in WT and $C^{\prime}$ strains (arrows). Bar indicates $100 \mathrm{~nm}$. 


\subsection{MbsA Down-Regulates Gliotoxin Biosynthesis}

To further characterize the complex role of MbsA, we performed RNA-seq analysis using $\triangle m b s A$ and WT strains. Notably, transcripts levels of the gliotoxin (GT) biosynthetic genes gliF encoding a cytochrome P450 oxidoreductase and gliA encoding an MFS GT efflux transporter were over 100-fold higher in the $\triangle m b s A$ mutant than WT strain (Supplementary Table S1). As shown in Figure 7A, most of the GT biosynthetic clustered genes were upregulated by $\triangle m b s A$. To corroborate the RNA-seq results, we examined mRNA levels of four gli genes by RT-qPCR. Levels of gliA, gliM, gliP, and gliT transcripts were significantly higher (4 to 68-fold) in $\triangle m b s A$ strain compared to those of WT and $C^{\prime}$ strains (Figure 7B) suggesting that the mutant strain may produce more GT than WT and complemented strain. To confirm this, we assessed levels of GT in WT, $\Delta m b s A$, and $C^{\prime}$ strains, and found that the $\triangle m b s A$ mutant produced about 5-fold more GT and other secondary metabolites compared to WT and $\mathrm{C}^{\prime}$ strains (Figure 7C).

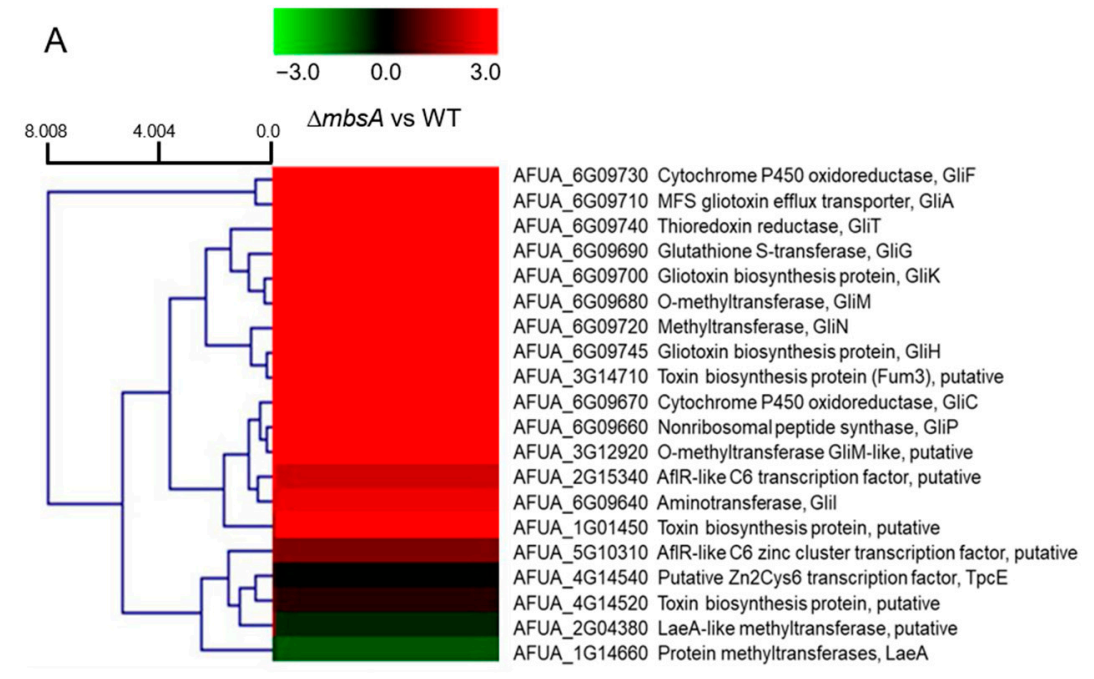

B

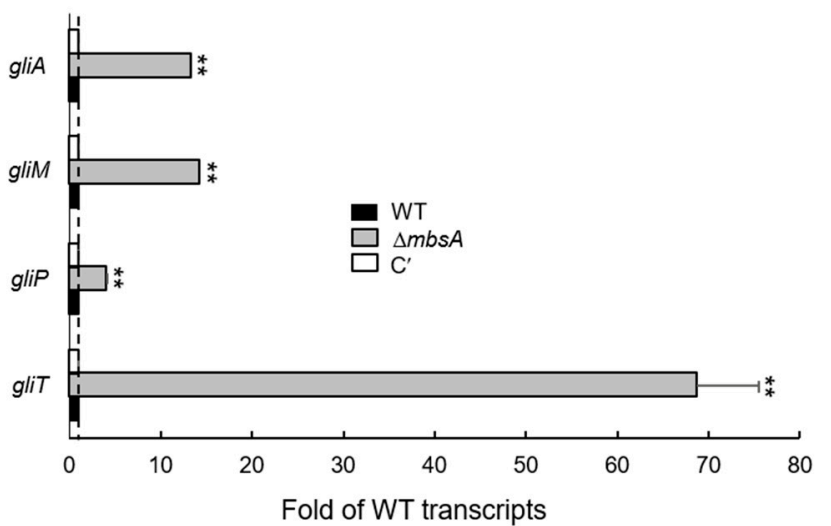

C

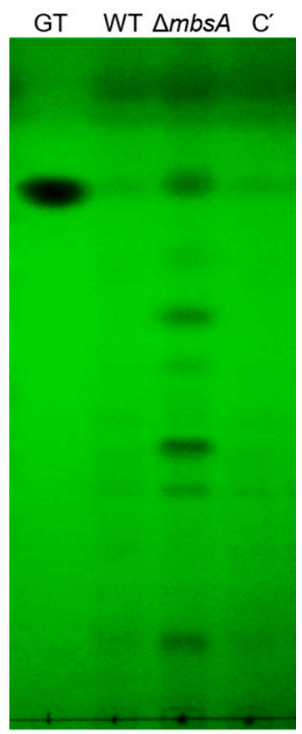

Figure 7. MbsA down-regulates gliotoxin (GT) production. (A) Heat map of those genes encoding toxin-related proteins. Most of gliotoxin biosynthetic genes were up-regulated by the loss of $m b s A$. (B) Determination of GT production in WT, $\triangle m b s A$, and $C^{\prime}$ strains. The culture supernatant of each strain was extracted with chloroform and subjected to TLC. (C) RT-qPCR analysis of GT-related genes in WT, $\triangle m b s A$, and $C^{\prime}$ strains. The ef1 $\alpha$ gene as the endogenous control. Statistical differences between WT and mutant strains were evaluated with ANOVA test: ${ }^{* *} p<0.01$.

\subsection{Mbs A Plays an Important Role in Virulence}

To investigate the pathological significance of the MbsA protein during A. fumigatus infection, conidia of WT, $\triangle m b s A$, and $C^{\prime}$ strains were intranasally introduced to neutropenic mice, which were generated by combinatorial administrations of cyclophosphamide and 
cortisone acetate (Figure 8A). Pathological outcomes were monitored by mouse survivability. In the survival curve analysis, while a group infected with WT and $C^{\prime}$ strain showed the first mortality on 2.5 days after infection and displayed $10 \%$ survival rate within 3.5 days, a group infected with the $\triangle m b s A$ mutant showed the first death on 2.5 days and $90 \%$ survival rate even after 5 days ( $p=0.0003$ ) (Figure $8 \mathrm{~B}$ ). Next, to understand why the $m b s A$ deletion led to less severity in mouse survivability, lung tissue sections were prepared from mice infected with three strains' conidia and stained with Hematoxylin and Eosin (H\&E) and Periodic acid-Schiff (PAS) to observe the extent of tissue damage and hyphal growth. In H\&E staining, WT infected lung tissue showed severe lung damages with disruption of alveolar structure and bronchial wall and necrosis around bronchial region. However, compared to WT, $\triangle m b s A$ led to mild disruption of the basement of bronchial wall. $C^{\prime}$ strain regained severe fungal damages which were similar to that caused by WT infection. Of note, as shown by PAS staining, the different lung tissue damages were associated with the extent of hyphal germination, which was much less in $\triangle m b s A$ strain infection than WT and $C^{\prime}$ strain infection (Figure $8 \mathrm{C}$ ). In addition, loss of $m b s A$ significantly decreased (about 20 -fold) the pulmonary fungal burden of mice (Figure $8 \mathrm{D}$ ).

A

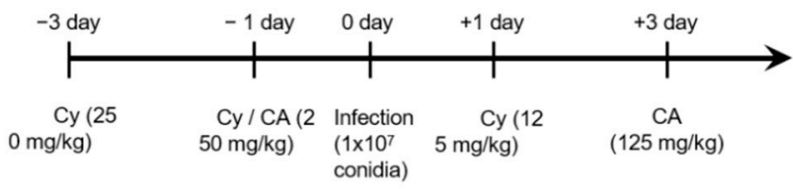

B

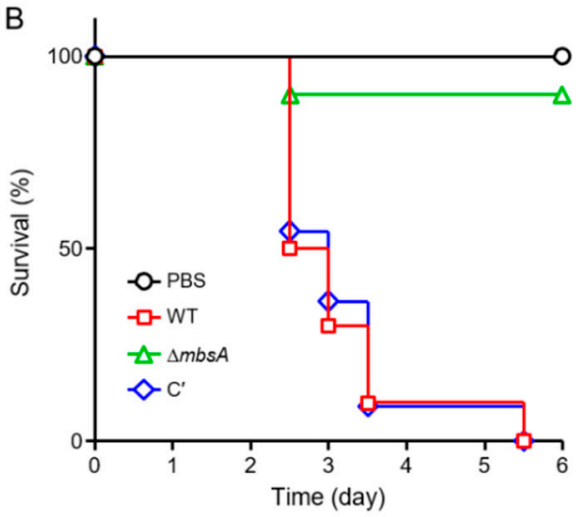

C

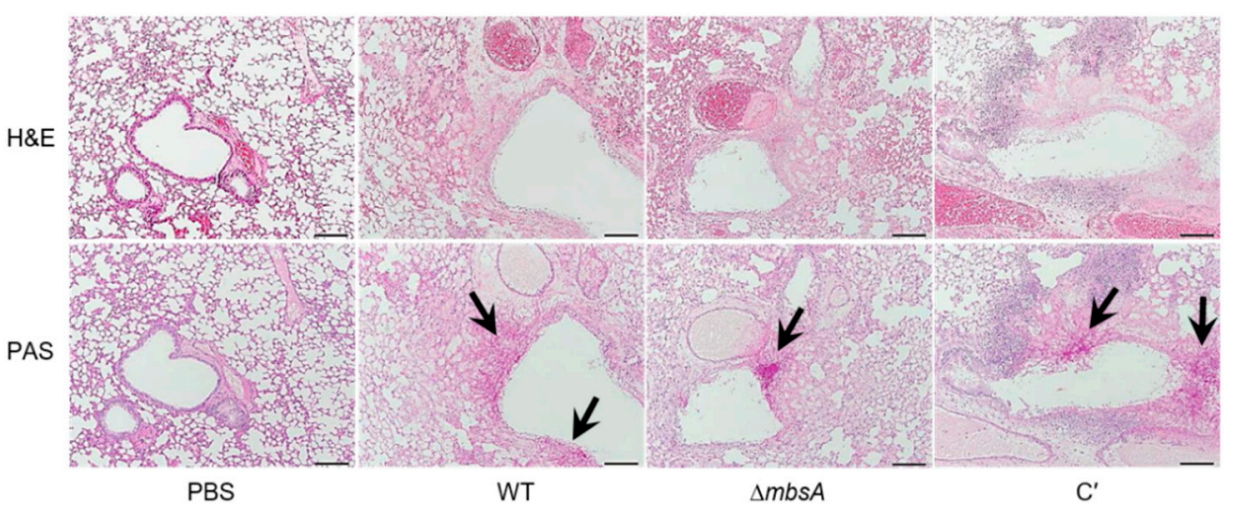

D

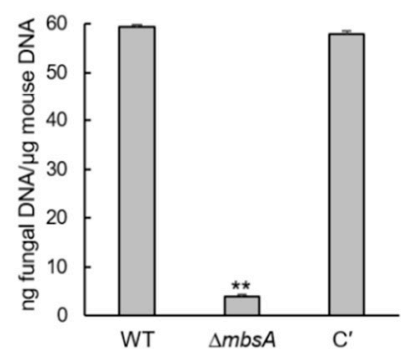

Figure 8. MbsA's role in virulence. (A) Schematic presentation of A. fumigatus infection in immunocompromised mouse model. Six-week-old female ICR mice were immunocompromised by treatment of cyclophosphamide (Cy, $250 \mathrm{mg} / \mathrm{kg}$ at day -3 and -1 and $125 \mathrm{mg} / \mathrm{kg}$ at day +1$)$ and cortisone acetate $(\mathrm{CA}, 250 \mathrm{mg} / \mathrm{kg}$ at day -1 and $125 \mathrm{mg} / \mathrm{kg}$ at day +3$)$. On day 0 mice were intranasally infected. (B) Survival curve of mice infected with WT, $\Delta m b s A$, and $C^{\prime}$ strains ( $n=10 /$ group). (C) Lung sections after each strains infection were stained with Hematoxylin and Eosin (H\&E) or Periodic-acid Schiff (PAS). Arrows indicate fungal mycelium. Bars indicate $200 \mu \mathrm{m}$. (D) Fungal burden in the lungs of mice infected with WT and $\triangle m b s A$, and $C^{\prime}$ strains. Data are represented as mean \pm standard deviation from three independent experiments. ANOVA test: ${ }^{* *} p<0.01$. 


\section{Discussion}

The APSES TF family function as key regulators of differentiation, vegetative growth, and asexual and sexual development from plant to fungi. However, a systematic investigation of their roles in A. fumigatus is not fully performed yet. Among the five predicted APSES TFs, only StuA and RgdA have been studied in A. fumigatus [6-8,10-12]. MbsA of A. fumigatus is phylogenetically unrelated with RgdA of the same fungus, or Mbp1 of budding yeast $S$. cerevisiae (Figure 1). The deletion of $m b s A$ resulted in decreased mycelial growth, conidiation, germination, and reduced mRNA levels of key asexual sporulation genes compared to WT (Figure 2). To elucidate the mechanism of delayed growth in $\triangle m b s A$ mutant, we analyzed the expression of $d p r$ genes, which are down-regulated conidial germination [13]. The expression levels of three $\mathrm{dpr}$ genes were significantly increased by the loss of $m b s A$, suggesting that the mutant strain showed delayed growth may due to suppress conidial germination (Supplementary Figure S1). Based on these, we propose that MbsA of A. fumigatus is necessary for normal growth and proper asexual development similar to RgdA.

Fungi are able to sense and respond external stress for survival in harsh environmental conditions and this ability is a key factor for the establishment of a successful infection [14]. The $\triangle m b s A$ strain was more sensitive to chitin synthesis inhibitor, Nikkomycin $Z$, and expressed lower levels of chitin synthesis genes (Figure 3). Chitin is a $\beta-1,4$-linked homopolymer of $\mathrm{N}$-acetyl glucosamine (GlcNAc) and its synthesis is important for hyphal development. Chitin synthase (CHS) catalyzes GlcNAc polymerization from UDP-GlcNAc and CHS appears to play important roles in chitin synthesis in hyphal tips and conidia, as well as in polarized hyphal growth [15-18]. Deletion of CHS genes lead to reduced hyphal growth and periodic swellings along hyphal lengths [19].

Previous studies described that SakA plays an important role in fungal cell wall integrity. The deletion of sakA displayed alterations in cell wall composition and significant increased sensitivity to cell wall-damaging agents, and the cell wall-targeting antifungals caspofungin and nikkomycin Z [20]. In addition, activation of the MpkA cell wall integrity MAPK pathway in response to osmotic or cell wall stress was largely dependent on SakA and MpkC [20]. In Aspergillus, MpkA-RlmA signaling is involved in the transcriptional activation of cell wall-related genes, such as $\operatorname{chs} A$, chs $C$, and $\operatorname{chs} E$ [21-23]. In accordance with these findings, the expression level of $\operatorname{rm} A$ and the phosphorylation levels SakA and MpkA were lowered by the loss of $m b s A$ (Figure 4). Collectively, we proposed that MbsA regulates cell wall integrity through properly activating the SakA MAPK pathway.

Like $\operatorname{RgdA}, \mathrm{MbsA}$ is also required for the conidia hydrophobicity, synthesis of the hydrophobin RodA protein, and conidia cell wall architecture (Figures 5 and 6). The ability of air-borne conidia to reach alveoli is primarily dependent on the hydrophobic rodlets layer, which promotes the dispersion of spores [24]. In addition, the rodlet layer interferes with the recognition of spores by the human immune system [25]. In A. fumigatus, seven hydrophobins (RodA to RodG) are identified [26] and only RodA is responsible for the rodlet formation, permeability, hydrophobicity, and immune-inertia of conidia cell wall surface [26]. Deletion of $\operatorname{rod} A$ modifies the properties of the conidia cell wall surface and effects on the drug sensitivity of the fungi [26]. Despite rodB transcript being highly expressed in the absence of $m b s A$, the rodlet layer is not formed in the mutant strain indicating that RodB is not essential in the conidial hydrophobicity and formation of rodlets as previously reported [26]. Our results have revealed that MbsA regulates expression of RodA and formation of the proper rodlet layer, and the absence of $m b s A$ may cause defects in fungal pathogenicity, and RgdA plays an identical role in these.

The APSES TF StuA has been shown to positively regulate the clustered aflatoxin biosynthetic genes in A. flavus and several secondary metabolite biosynthetic cluster genes in A. fumigatus [7,27]. In contrast, MbsA in A. fumigatus represses expression of the GT clustered genes and production of GT, similar to RgdA [8] (Figure 7). As a result, the $\Delta m b s A$ mutant produced significantly higher amount of GT than WT and $C^{\prime}$ strains. Interestingly, despite elevated GT production, the virulence of the mutant in the murine model was 
greatly reduced by the loss of $m b s A$ (Figure 8). Our histological and fungal burden studies with the infected mice showed that the deletion of $m b s A$ resulted in milder necrosis and disruption of bronchiole region compared to those found in WT and $\mathrm{C}^{\prime}$ strains. Furthermore, $\triangle m b s A$ significantly decreased the pulmonary fungal burden of mice (Figure 8). Collectively, regardless of the elevated levels of GT, the absence of $m b s A$ leads to reduced virulence, which may be associated with the lowered conidial hydrophobicity and rodlet layer, and the attenuated SakA MAPK pathway.

Taken together, MbsA plays similar roles with RgdA in governing fungal growth, differentiation, secondary metabolism, and virulence may be due to belong to same group (clade A) [28]. However, MbsA regulates the SakA MAP kinase pathway contrary to RgdA.

In summary, we propose a genetic model depicting the complex role of Mbs in A. fumigatus (Figure 9). In this model, MbsA positively acts at or upstream of the stress activated SakA MAPK signaling pathways, which activates chitin biosynthesis. While MbsA up-regulates asexual developmental activators and the subsequent RodA production, represses expression of the GT gene clusters and production of GT. Additional studies are needed to identify detailed molecular mechanism of MbsA and interaction with RgdA or other APSES TFs in A. fumigatus.

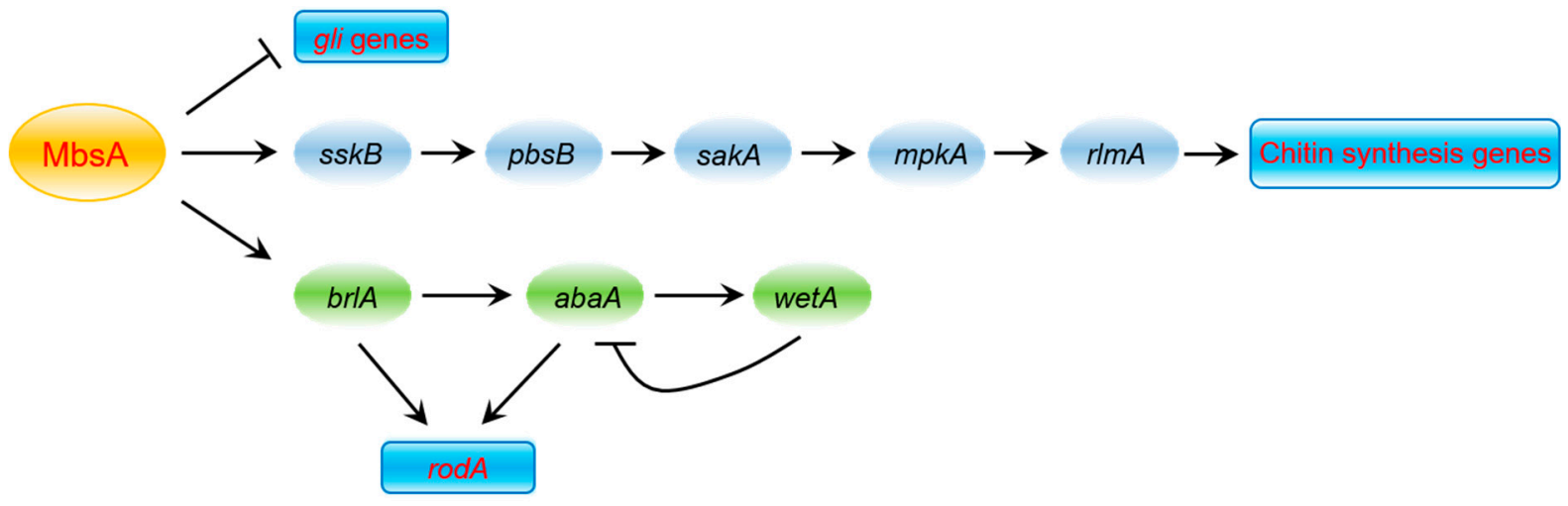

Figure 9. A genetic model depicting the role of MbsA in A. fumigatus. MbsA positively regulates asexual sporulation, rodA expression, the SakA MAP kinase pathway, and virulence, but negatively controls expression of gliotoxin-related genes and GT production.

\section{Materials and Methods}

\subsection{Strains and Culture Conditions}

A. fumigatus AF293.1 (AfpyrG1) was used to generate the $\triangle m b s A$ mutant and AF293 was used as a wild type (WT). Fungal strains were grown on glucose minimal medium (MMG) or MMG with 0.1\% yeast extract (MMY) with appropriate supplements as described previously [29]. For the production of a colony on solid medium, porous cellophane was deposited on the surface of the agar and point-inoculated with about $10^{5}$ conidia onto the cellophane. The petri dishes were incubated in the dark at $37^{\circ} \mathrm{C}$ for 3 days. Fungal tissue was collected using a sterile spatula and used for RNA extraction. For asexual developmental induction, about $5 \times 10^{5}$ conidia/mL of WT and relevant mutant strains were inoculated in $500 \mathrm{~mL}$ of liquid MMY and incubated at $37^{\circ} \mathrm{C}$ and $250 \mathrm{rpm}$ for $16 \mathrm{~h}$. The mycelium was harvested by filtering through Miracloth (Calbiochem, San Diego, CA, USA), transferred to solid MMY, and incubated at $37{ }^{\circ} \mathrm{C}$ for air-exposed asexual developmental induction. Samples were collected at various time points post asexual developmental induction.

\subsection{Generation of the $\Delta m b s A$ Mutant in A. fumigatus}

The deletion construct generated employing double-joint PCR [30] containing the $A$. nidulans selective marker (AnipyrG) with the $5^{\prime}$ and $3^{\prime}$ franking regions of the $A$. fumigatus mbsA gene (Afu3g13920) was introduced into the recipient strains [31]. The selective 
marker was amplified from A. nidulans FGSC A4 genomic DNA with the primer pair oligo697/oligo698. The null mutant colonies were isolated and confirmed by diagnostic PCR (oligo378/oligo379), followed by restriction enzyme digestion. To complement the $m b s A$ null mutant, a double-joint PCR (DJ-PCR) method was used [30] with hygB as the selective marker. The oligonucleotides used in this study are listed in Supplementary Table S2.

\subsection{Nucleic Acid Isolation and Manipulation}

Total RNA isolation and quantitative RT-PCR (RT-qPCR) assays were performed as previously described [32-34]. Briefly, each sample was homogenized in $1 \mathrm{~mL}$ of TRIzol reagent (Invitrogen, Waltham, MA, USA) using a Mini-Bead Beater (BioSpec Products, Bartlesville, OK, USA) and $0.3 \mathrm{~mL}$ of Zirconia/Silica beads (RPI, Mt. Prospect, IL, USA). The supernatant was mixed with an equal volume of iced isopropanol and centrifuged again. The RNA pellets were washed with $70 \%$ ethanol by diethyl pyrocarbonate (DEPC) treated water and dissolved in the RNase-free water. RNA quality was checked by spectrophotometer and Bioanalyzer 2100 system (Agilent, Santa Clara, CA, USA). RT-qPCRs were performed using a Rotor-Gene Q (Qiagen, Hilden, Germany). Each run was assayed in triplicate in a total volume of $20 \mu \mathrm{L}$ containing the RNA template, One Step RT-PCR SYBR Mix (Doctor Protein, Korea), reverse transcriptase, and 10 pmole of each primer. Reverse transcription was carried out at $42^{\circ} \mathrm{C}$ for $30 \mathrm{~min}$. PCR conditions were $95^{\circ} \mathrm{C} / 5 \mathrm{~min}$ for one cycle, followed by $95^{\circ} \mathrm{C}$ and $55^{\circ} \mathrm{C} / 30$ s for 40 cycles. Amplification of one specific target DNA was checked by melting curve analysis. The expression ratios were normalized to reference gene ef1 $\alpha$ expression $[35,36]$ and calculated according to the $\Delta \Delta \mathrm{Cq}$ method [37]. The expression stability of ef1 $\alpha$ was determined by BestKeeper index via RefFinder (https: / / www.heartcare.com.au/reffinder/, accessed on 2 April 2021) [38] and PCR efficiencies of studied genes were $89.5-101.8 \%$. Expression of target genes mRNA was analyzed with appropriate oligonucleotide pairs (Table S3). For RNA-seq analyses, 3-days-old culture of WT and mutant strains were harvested from solid MMY. Total RNA was extracted and submitted to eBiogen Inc. (Seoul, Korea) for library preparation and sequencing.

\subsection{Measurement of Germination Rate and Yield of Conidia}

To examine conidia germination levels, conidia of WT and mutants were inoculated into $5 \mathrm{~mL}$ MMY broth at a concentration of $2 \times 10^{5}$ conidia $/ \mathrm{mL}$ and incubated at $37^{\circ} \mathrm{C}$. Two hours after inoculation, germination was assessed every $2 \mathrm{~h}$. Three random visual fields were observed microscopically. The percentage of germination was calculated by the number of total conidia and germinated conidia in the visual field. To determine conidia number, conidial suspension (about $10^{6}$ conidia) of three strain was spread on to MMY solid media and incubated in the dark at $37^{\circ} \mathrm{C}$. At the indicated time, conidia were collected with $0.5 \%$ Tween 80 solution from the plate and filtered through Miracloth (Calbiochem, San Diego, CA, USA), and counted using a hemocytometer.

\subsection{Determination of the Conidial Hydrophobicity}

The hydrophobicity of conidia cell wall was determined as described previously with a detergent solution (0.2\% SDS, $50 \mathrm{mM}$ EDTA) [8]. Hydrophobicity was also assessed by aqueous-solvent partitioning assays, using the microbial adhesion to solvents (MATS) method [39]. Briefly, $2 \mathrm{~mL}$ of conidial suspension in $0.1 \mathrm{M} \mathrm{KNO}_{3}\left(2\right.$ to $7 \times 10^{6}$ conidia/mL) were vortexed vigorously with $400 \mu \mathrm{L}$ of hexadecane for $2 \mathrm{~min}$. After separation of the two phases, an aliquot of the aqueous phase was collected, and the number of conidia in the aqueous phase was determined using a hemocytometer. The percentage of bound conidia to solvent was calculated as follows: \% adhesion to solvent $=\left(1-\mathrm{N} / \mathrm{N}_{0}\right) \times 100$ where $\mathrm{N}_{0}$ is the initial number of conidia in the aqueous phase and $\mathrm{N}$ is the residual number of conidia in the aqueous phase after partitioning. The RodA protein was extracted by incubating dry spores with hydrofluoric acid (HF) $(10 \mu \mathrm{L}$ per mg dry weight) for $72 \mathrm{~h}$ at 
$4{ }^{\circ} \mathrm{C}$ [25]. The full obtained protein was reconstituted in Laemmli's sample buffer, and subjected to SDS-PAGE analysis and visualized by Coomassie Brilliant Blue staining.

\subsection{Microscopy}

TEM and AFM analysis was carried out at the Korea Basic Science Institute. For TEM analysis, conidia were fixed in $2.5 \%$ glutaraldehyde in $0.1 \mathrm{M}$ phosphate, washed three times with $0.1 \mathrm{M}$ phosphate, post-fixed in $1 \%$ osmium tetroxide, incubated for $1 \mathrm{~h}$ in $0.1 \mathrm{M}$ phosphate, and dehydrated for $15 \mathrm{~min}$ in a graded methanol series from $50 \%$ to $100 \%$. Samples were embedded in Epon resin 812. The sections were examined with a Tecnai G2 Spirit Twin Bio-Transmission Electron Microscope (FEI, Hillsboro, OR, USA), with an accelerating voltage of $120 \mathrm{KV}$. Conidial surfaces were analyzed by a Nanoscope V Multimode 8 AFM (Bruker, Santa Barbara, CA, USA). Conidia were immobilized by mechanically trapping them into porous polycarbonate membranes. After filtering a concentrated suspension of conidia, the filter was rinsed with deionized water, carefully cut, and attached to a metallic puck using double-sided sticky tape. Images were performed in soft tapping mode using a silicon AFM probe $(\mathrm{k}=42 \mathrm{~N} / \mathrm{m}, \mathrm{f}=320 \mathrm{kHz}, \mathrm{NCHR}$, Nanoworld, Neuchâtel, Switzerland).

\subsection{Transcriptome Analysis}

For control and test RNAs, the construction of library was performed using QuantSeq $3^{\prime}$ mRNA-Seq Library Prep Kit (Lexogen, Inc., Wien, Austria) according to the manufacturer's instructions. High-throughput sequencing was performed as single-end 75 sequencing using NextSeq 500 (Illumina, Inc., San Diego, CA, USA). QuantSeq 3' mRNA-Seq reads were aligned using Bowtie2 [40]. Bowtie2 indices were either generated from genome assembly sequence or the representative transcript sequences for aligning to the genome and transcriptome. The alignment file was used for assembling transcripts, estimating their abundances and detecting differential expression of genes. Differentially expressed gene were determined based on counts from unique and multiple alignments using coverage in Bedtools [41]. The RT (Read Count) data were processed based on Quantile normalization method using EdgeR within R (R development Core Team, 2016) using Bioconductor [42]. Gene classification was based on searches done by DAVID (http:/ / david.abcc.ncifcrf.gov/, accessed on 15 July 2018) and Medline databases (http://www.ncbi.nlm.nih.gov/, accessed on 15 July 2018). Hierarchical clustering performed using ExDEGA (Excel based Differentially Expressed Gene Analysis) Program (ver. 3.0, ebiogen Inc., Seoul, Korea).

\subsection{Detection of Gliotoxin (GT)}

Amount of GT was determined by the thin layer chromatography (TLC) method as described previously [43]. Conidia (about $10^{5}$ ) of each strain were inoculated into $5 \mathrm{~mL}$ of liquid complete medium and cultured at $37^{\circ} \mathrm{C}$ for 7 days under dark conditions. After incubation, an equal amount of chloroform was added per sample. Samples were centrifuged for $10 \mathrm{~min}$. The separated organic phase was transferred to new glass vials and evaporated. Samples were resuspended in $50 \mu \mathrm{L}$ of methanol and $10 \mu \mathrm{L}$ loaded into a thinlayer chromatography (TLC). The TLC Silicagel 60 plate was developed with toluene/ethyl acetate/formic acid $(5: 4: 1, v / v / v)$.

\subsection{Murine Virulence Assay}

For the immunocompromised mouse model, we used outbred CrlOri: CD1 (ICR) (Orient Bio Inc., Korea) female mice ( $30 \mathrm{~g}$ in body weight, 6 to 8 weeks old), which were housed five per cage and had access to food and water ad libitum. Mice were immunosuppressed by treatment of cyclophosphamide and cortisone (Figure 8A). For conidia inoculation, mice were anesthetized with isoflurane and then intranasally infected with $1 \times 10^{7}$ conidia of $A$. fumigatus strains (10 mice per each fungal strain) in $30 \mu \mathrm{L}$ of $0.01 \%$ Tween 80 in PBS. Mice were monitored every $12 \mathrm{~h}$ for survival for 5 days after the challenge. Mock mice included in all experiments were inoculated with sterile $0.01 \%$ Tween 
80 in PBS. Mice were checked every $12 \mathrm{~h}$ for survival and Kaplan-Meier survival curves were analyzed using the Log-Rank (Mantel-Cox) test for significance $(p<0.05)$.

\subsection{Immunoblotting}

Total soluble proteins were extracted from $\mathrm{WT}$, mutant, and $\mathrm{C}^{\prime}$ strains subjected to 0 and $20 \mathrm{~min}$ with $10 \mathrm{mg} / \mathrm{mL}$ CFW treatment. Samples were separated using $12 \%$ SDS-PAGE and blotted onto nitrocellulose membrane. Blot was analyzed with anti-phospho-p38 MAPK antibody (New England Biolabs, MA, USA) and anti-phospho-p44/42 MAPK antibody (Cell Signaling Technologies, Danvers, MA, USA).

Supplementary Materials: The following are available online at https:/ / www.mdpi.com/article/10 .3390 /ijms22073777/s1, Figure S1: Expression of dpr genes, Table S1: Differentially expressed toxin related genes in $\triangle m b s A$ relative to WT strain, Table S2: Oligonucleotides used in this study.

Author Contributions: K.-S.S. and J.-H.Y. conceived and supervised the study; K.-S.S., J.-H.Y., and M.-W.L. designed experiments; Y.-H.C., S.-C.J., and K.-S.S. performed experiments; Y.-H.C., S.-C.J., and K.-S.S. analyzed data; M.-W.L., J.-H.Y., and K.-S.S. wrote the manuscript. All authors have read and agreed to the published version of the manuscript.

Funding: National Research Foundation of Korea (NRF) grant funded by the Korea government (MOE) (No. 2020R111A3051661) and (No. 2020R1A6A3A13053167).

Institutional Review Board Statement: All of the animal procedures in this study were reviewed and approved by the Institutional Animal Care and Use Committee of Daejeon University (DJUARB2019024, 19 August 2020).

Informed Consent Statement: Not applicable.

Data Availability Statement: The RNA-seq data are available from NCBI Gene Expression Omnibus (GEO) database (GSE123744).

Acknowledgments: This work was supported by the National Research Foundation of Korea (NRF) grant funded by the Korea government (MOE) (No. 2020R111A3051661) to K.-S.S. and (No. 2020R1A6A3A13053167) to Y.-H.C. The work at UW was supported by Food Research Institute and the University of Wisconsin-Madison Office of the Vice Chancellor for Research and Graduate Education (OVCRGE) with funding from the Wisconsin Alumni Research Foundation to J.-H.Y.

Conflicts of Interest: We declare no conflict of interests.

\section{References}

1. Zhao, Y.; Su, H.; Zhou, J.; Feng, H.; Zhang, K.Q.; Yang, J. The APSES family proteins in fungi: Characterizations, evolution and functions. Fungal Genet. Biol. 2015, 81, 271-280. [CrossRef] [PubMed]

2. Dutton, J.R.; Johns, S.; Miller, B.L. StuAp is a sequence-specific transcription factor that regulates developmental complexity in Aspergillus nidulans. EMBO J. 1997, 16, 5710-5721. [CrossRef]

3. Stoldt, V.R.; Sonneborn, A.; Leuker, C.E.; Ernst, J.F. Efg1p, an essential regulator of morphogenesis of the human pathogen Candida albicans, is a member of a conserved class of bHLH proteins regulating morphogenetic processes in fungi. EMBO J. 1997, 16, 1982-1991. [CrossRef] [PubMed]

4. Sonneborn, A.; Bockmuhl, D.P.; Ernst, J.F. Chlamydospore formation in Candida albicans requires the Efg1p morphogenetic regulator. Infect. Immun. 1999, 67, 5514-5517. [CrossRef]

5. Doedt, T.; Krishnamurthy, S.; Bockmuhl, D.P.; Tebarth, B.; Stempel, C.; Russell, C.L.; Brown, A.J.; Ernst, J.F. APSES proteins regulate morphogenesis and metabolism in Candida albicans. Mol. Biol. Cell 2004, 15, 3167-3180. [CrossRef] [PubMed]

6. Sheppard, D.C.; Doedt, T.; Chiang, L.Y.; Kim, H.S.; Chen, D.; Nierman, W.C.; Filler, S.G. The Aspergillus fumigatus StuA protein governs the up-regulation of a discrete transcriptional program during the acquisition of developmental competence. Mol. Biol. Cell 2005, 16, 5866-5879. [CrossRef]

7. Twumasi-Boateng, K.; Yu, Y.; Chen, D.; Gravelat, F.N.; Nierman, W.C.; Sheppard, D.C. Transcriptional profiling identifies a role for BrlA in the response to nitrogen depletion and for StuA in the regulation of secondary metabolite clusters in Aspergillus fumigatus. Eukaryot. Cell 2009, 8, 104-115. [CrossRef]

8. Jun, S.C.; Choi, Y.H.; Lee, M.W.; Yu, J.H.; Shin, K.S. The Putative APSES Transcription Factor RgdA Governs Growth, Development, Toxigenesis, and Virulence in Aspergillus fumigatus. mSphere 2020, 5. [CrossRef] 
9. Song, M.H.; Lee, J.W.; Kim, M.S.; Yoon, J.K.; White, T.C.; Floyd, A.; Heitman, J.; Strain, A.K.; Nielsen, J.N.; Nielsen, K.; et al. A flucytosine-responsive Mbp1/Swi4-like protein, Mbs1, plays pleiotropic roles in antifungal drug resistance, stress response, and virulence of Cryptococcus neoformans. Eukaryot. Cell 2012, 11, 53-67. [CrossRef]

10. Miller, K.Y.; Wu, J.; Miller, B.L. StuA is required for cell pattern formation in Aspergillus. Genes Dev. 1992, 6, 1770-1782. [CrossRef]

11. Miller, K.Y.; Toennis, T.M.; Adams, T.H.; Miller, B.L. Isolation and transcriptional characterization of a morphological modifier: The Aspergillus nidulans stunted (stuA) gene. Mol. Gen. Genet. 1991, 227, 285-292. [CrossRef] [PubMed]

12. Lee, J.Y.; Kim, L.H.; Kim, H.E.; Park, J.S.; Han, K.H.; Han, D.M. A putative APSES transcription factor is necessary for normal growth and development of Aspergillus nidulans. J. Microbiol. 2013, 51, 800-806. [CrossRef] [PubMed]

13. Wong Sak Hoi, J.; Lamarre, C.; Beau, R.; Meneau, I.; Berepiki, A.; Barre, A.; Mellado, E.; Read, N.D.; Latge, J.P. A novel family of dehydrin-like proteins is involved in stress response in the human fungal pathogen Aspergillus fumigatus. Mol. Biol. Cell 2011, 22, 1896-1906. [PubMed]

14. Wezensky, S.J.; Cramer, R.A., Jr. Implications of hypoxic microenvironments during invasive aspergillosis. Med. Mycol. 2011, 49 (Suppl. 1), S120-S124. [CrossRef] [PubMed]

15. Rogg, L.E.; Fortwendel, J.R.; Juvvadi, P.R.; Steinbach, W.J. Regulation of expression, activity and localization of fungal chitin synthases. Med. Mycol. 2012, 50, 2-17. [CrossRef] [PubMed]

16. Borgia, P.T.; Iartchouk, N.; Riggle, P.J.; Winter, K.R.; Koltin, Y.; Bulawa, C.E. The chsB gene of Aspergillus nidulans is necessary for normal hyphal growth and development. Fungal Genet. Biol. 1996, 20, 193-203. [CrossRef]

17. Fukuda, K.; Yamada, K.; Deoka, K.; Yamashita, S.; Ohta, A.; Horiuchi, H. Class III chitin synthase ChsB of Aspergillus nidulans localizes at the sites of polarized cell wall synthesis and is required for conidial development. Eukaryot. Cell 2009, 8, 945-956. [CrossRef]

18. Yanai, K.; Kojima, N.; Takaya, N.; Horiuchi, H.; Ohta, A.; Takagi, M. Isolation and characterization of two chitin synthase genes from Aspergillus nidulans. Biosci. Biotechnol. Biochem. 1994, 58, 1828-1835. [CrossRef]

19. Aufauvre-Brown, A.; Mellado, E.; Gow, N.A.; Holden, D.W. Aspergillus fumigatus chsE: A gene related to CHS3 of Saccharomyces cerevisiae and important for hyphal growth and conidiophore development but not pathogenicity. Fungal Genet. Biol. 1997, 21, 141-152. [CrossRef]

20. Bruder Nascimento, A.C.; Dos Reis, T.F.; de Castro, P.A.; Hori, J.I.; Bom, V.L.; de Assis, L.J.; Ramalho, L.N.; Rocha, M.C.; Malavazi, I.; Brown, N.A.; et al. Mitogen activated protein kinases SakA(HOG1) and MpkC collaborate for Aspergillus fumigatus virulence. Mol. Microbiol. 2016, 100, 841-859. [CrossRef]

21. Rocha, M.C.; Fabri, J.H.; Franco de Godoy, K.; Alves de Castro, P.; Hori, J.I.; Ferreira da Cunha, A.; Arentshorst, M.; Ram, A.F.; van den Hondel, C.A.; Goldman, G.H.; et al. Aspergillus fumigatus MADS-Box Transcription Factor $r$ rmA Is Required for Regulation of the Cell Wall Integrity and Virulence. G3 Genes Genomes Genet. 2016, 6, 2983-3002.

22. Kovacs, Z.; Szarka, M.; Kovacs, S.; Boczonadi, I.; Emri, T.; Abe, K.; Pocsi, I.; Pusztahelyi, T. Effect of cell wall integrity stress and RlmA transcription factor on asexual development and autolysis in Aspergillus nidulans. Fungal Genet. Biol. 2013, 54, 1-14. [CrossRef]

23. Fujioka, T.; Mizutani, O.; Furukawa, K.; Sato, N.; Yoshimi, A.; Yamagata, Y.; Nakajima, T.; Abe, K. MpkA-Dependent and -independent cell wall integrity signaling in Aspergillus nidulans. Eukaryot. Cell 2007, 6, 1497-1510. [CrossRef]

24. Paris, S.; Debeaupuis, J.P.; Crameri, R.; Carey, M.; Charles, F.; Prevost, M.C.; Schmitt, C.; Philippe, B.; Latge, J.P. Conidial hydrophobins of Aspergillus fumigatus. Appl. Environ. Microbiol. 2003, 69, 1581-1588. [CrossRef] [PubMed]

25. Aimanianda, V.; Bayry, J.; Bozza, S.; Kniemeyer, O.; Perruccio, K.; Elluru, S.R.; Clavaud, C.; Paris, S.; Brakhage, A.A.; Kaveri, S.V.; et al. Surface hydrophobin prevents immune recognition of airborne fungal spores. Nature 2009, 460, $1117-1121$. [CrossRef] [PubMed]

26. Valsecchi, I.; Dupres, V.; Stephen-Victor, E.; Guijarro, J.I.; Gibbons, J.; Beau, R.; Bayry, J.; Coppee, J.Y.; Lafont, F.; Latge, J.P.; et al. Role of Hydrophobins in Aspergillus fumigatus. J. Fungi 2017, 4, 2. [CrossRef] [PubMed]

27. Yao, G.; Zhang, F.; Nie, X.; Wang, X.; Yuan, J.; Zhuang, Z.; Wang, S. Essential APSES Transcription Factors for Mycotoxin Synthesis, Fungal Development, and Pathogenicity in Aspergillus flavus. Front. Microbiol. 2017, 8, 2277. [CrossRef] [PubMed]

28. Longo, L.V.G.; Ray, S.C.; Puccia, R.; Rappleye, C.A. Characterization of the APSES-family transcriptional regulators of Histoplasma capsulatum. FEMS Yeast Res. 2018, 18, foy087. [CrossRef]

29. Kafer, E. Meiotic and mitotic recombination in Aspergillus and its chromosomal aberrations. Adv. Genet. 1977, $19,33-131$.

30. Yu, J.H.; Hamari, Z.; Han, K.H.; Seo, J.A.; Reyes-Dominguez, Y.; Scazzocchio, C. Double-joint PCR: A PCR-based molecular tool for gene manipulations in filamentous fungi. Fungal Genet. Biol. 2004, 41, 973-981. [CrossRef]

31. Szewczyk, E.; Nayak, T.; Oakley, C.E.; Edgerton, H.; Xiong, Y.; Taheri-Talesh, N.; Osmani, S.A.; Oakley, B.R. Fusion PCR and gene targeting in Aspergillus nidulans. Nat. Protoc. 2006, 1, 3111-3120. [CrossRef] [PubMed]

32. Shin, K.S.; Kim, Y.H.; Yu, J.H. Proteomic analyses reveal the key roles of BrlA and AbaA in biogenesis of gliotoxin in Aspergillus fumigatus. Biochem. Biophys. Res. Commun. 2015, 463, 428-433. [CrossRef]

33. Mah, J.H.; Yu, J.H. Upstream and downstream regulation of asexual development in Aspergillus fumigatus. Eukaryot. Cell 2006, 5, 1585-1595. [CrossRef] [PubMed]

34. Han, K.H.; Seo, J.A.; Yu, J.H. A putative G protein-coupled receptor negatively controls sexual development in Aspergillus nidulans. Mol. Microbiol. 2004, 51, 1333-1345. [CrossRef] [PubMed] 
35. Song, H.; Dang, X.; He, Y.Q.; Zhang, T.; Wang, H.Y. Selection of housekeeping genes as internal controls for quantitative RT-PCR analysis of the veined rapa whelk (Rapana venosa). PeerJ 2017, 5, e3398. [CrossRef]

36. Huan, P.; Wang, H.; Liu, B. Assessment of housekeeping genes as internal references in quantitative expression analysis during early development of oyster. Genes Genet. Syst. 2017, 91, 257-265. [CrossRef]

37. Livak, K.J.; Schmittgen, T.D. Analysis of relative gene expression data using real-time quantitative PCR and the $2^{-\Delta \Delta C T}$ Method. Methods 2001, 25, 402-408. [CrossRef]

38. Pfaffl, M.W.; Tichopad, A.; Prgomet, C.; Neuvians, T.P. Determination of stable housekeeping genes, differentially regulated target genes and sample integrity: BestKeeper-Excel-based tool using pair-wise correlations. Biotechnol. Lett. 2004, 26, 509-515. [CrossRef]

39. Mortensen, H.D.; Gori, K.; Jespersen, L.; Arneborg, N. Debaryomyces hansenii strains with different cell sizes and surface physicochemical properties adhere differently to a solid agarose surface. FEMS Microbiol. Lett. 2005, 249, 165-170. [CrossRef]

40. Langmead, B.; Salzberg, S.L. Fast gapped-read alignment with Bowtie 2. Nat. Methods 2012, 9, 357-359. [CrossRef]

41. Quinlan, A.R.; Hall, I.M. BEDTools: A flexible suite of utilities for comparing genomic features. Bioinformatics 2010, 26, 841-842. [CrossRef] [PubMed]

42. Gentleman, R.C.; Carey, V.J.; Bates, D.M.; Bolstad, B.; Dettling, M.; Dudoit, S.; Ellis, B.; Gautier, L.; Ge, Y.; Gentry, J.; et al. Bioconductor: Open software development for computational biology and bioinformatics. Genome Biol. 2004, 5, R80. [CrossRef] [PubMed]

43. Bok, J.W.; Keller, N.P. LaeA, a regulator of secondary metabolism in Aspergillus spp. Eukaryot. Cell 2004, 3, 527-535. [CrossRef] [PubMed] 